\title{
Zeolite-based hemostat QuikClot releases calcium into blood and promotes blood coagulation in vitro
}

\author{
Jing $\mathrm{LI}^{1, \#}$, Wei CAO ${ }^{2, \#}$, Xiao-xing $\mathrm{LV}^{1}$, $\mathrm{Li}_{\mathrm{JIANG}}{ }^{1}$, Yue-jun $\mathrm{LI}^{1}$, Wang-zhou $\mathrm{LI}^{1}$, Shao-zong $\mathrm{CHEN}^{1, *}$, Xue-yong $\mathrm{LI}^{1, \text { * }}$ \\ ${ }^{1}$ Department of Burns and Plastic Surgery, Tangdu Hospital, the Fourth Military Medical University, Xi-an 710038, China; ${ }^{2}$ Depart- \\ ment of Interventional Radiology, Tangdu Hospital, the Fourth Military Medical University, Xi-an 710038, China
}

\begin{abstract}
Aim: To examine the changes in electrolyte concentrations after addition of zeolite-based hemostat QuikClot in blood and the effects of zeolite on blood coagulation in vitro.

Methods: Fresh blood was taken from healthy adult volunteers and sheep, and the electrolyte concentrations in blood were measured using a blood electrolyte analyzer. Zeolite Saline Solution (ZSS) was prepared by addition of $2 \mathrm{~g}$ zeolite to $0.9 \% \mathrm{NaCl}$ solution $(4,8$, or $16 \mathrm{~mL}$ ). The electrolytes in ZSS were measured using inductively coupled plasma atomic emission spectroscopy. The prothrombin time (PT) and activated partial thromboplastin time (APTT) of blood were measured using the test tube method. The activated clotting time (ACT) and clotting rate (CR) of blood were measured with Sonoclot Coagulation and Platelet Function Analyzer.

Results: Addition of zeolite (50 and $100 \mathrm{mg}$ ) in $2 \mathrm{~mL}$ human blood significantly increased $\mathrm{Ca}^{2+}$ concentration, while $\mathrm{Na}^{+}$and $\mathrm{K}^{+}$ concentrations were significantly decreased. Addition of zeolite (50 and $100 \mathrm{mg}$ ) in $0.9 \% \mathrm{NaCl}$ solution $(2 \mathrm{~mL})$ caused similar changes in $\mathrm{Ca}^{2+}$ and $\mathrm{Na}^{+}$concentrations. $\mathrm{Si}^{4+}(0.2434 \mathrm{~g} / \mathrm{L})$ and $\mathrm{Al}^{3+}(0.2575 \mathrm{~g} / \mathrm{L})$ were detected in ZSS $(2 \mathrm{~g} / 8 \mathrm{~mL})$. Addition of ZSS in sheep blood shortened APTT in a concentration dependent manner, without changing PT. ZSS or aqueous solution of $\mathrm{CaCl}_{2}$ that contained $\mathrm{Ca}^{2+}$ concentration identical to that of ZSS significantly shortened ACT in human blood without significantly changing $\mathrm{CR}$, and the effect of ZSS on ACT was not significantly different from that of $\mathrm{CaCl}_{2}$.

Conclusion: Zeolite releases $\mathrm{Ca}^{2+}$ into blood, thus accelerating the intrinsic pathway of blood coagulation and shortening the clot formation time.
\end{abstract}

Keywords: hemostatics; QuikClot; zeolites; electrolytes; calcium; blood coagulation; prothrombin time; activated partial thromboplastin time; activated clotting time; clotting rate

Acta Pharmacologica Sinica (2013) 34: 367-372; doi: 10.1038/aps.2012.159; published online 21 Jan 2013

\section{Introduction}

The zeolite-based hemostat QuikClot (QC) is a promising hemostatic agent that has been approved by the Food and Drug Administration (FDA) for the treatment of uncontrolled life-threatening hemorrhage. Zeolite exhibits distinct advantages in stability, accessibility and cost efficiency with no biological toxicity or risk of disease transmission. Animal studies have demonstrated the efficacy of zeolite in the stabilization of severe arterial hemorrhage $\mathrm{e}^{[1]}$ and diffuse, long-term bleeding from lethal liver injuries ${ }^{[2,3]}$. The life-saving properties of QC have been confirmed under combat conditions in soldiers with uncontrolled bleeding ${ }^{[4,5]}$. QC has been used in civilian emergency settings because of its clinical value and treatment

\footnotetext{
\# These authors contributed equally to this work.

* To whom correspondence should be addressed.

E-mail cszong@fmmu.edu.cn (Shao-zong CHEN); yuyong@fmmu.edu.cn (Xue-yong LI)

Received 2012-07-02 Accepted 2012-10-18
}

advantages.

However, several issues have emerged from the medical use of QC. First, zeolite produces an exothermic reaction when it comes into contact with blood, and the dramatic temperature increase damages tissues and causes injury ${ }^{[6]}$. Second, the agent is difficult to completely remove from the wound following application and may lead to the formation of inflammatory granulomas or abscesses because of foreign body reactions ${ }^{[7]}$. The current instructions for $\mathrm{QC}$ use are limited to the treatment of external sources of life-threatening hemorrhage that are uncontrollable by all other clinical means. These problems may be resolved by modification of the material properties of QC: for example, by altering the composition or structure of the material to enhance its hemostatic efficacy and reduce its side effects ${ }^{[8,9]}$. However, the mechanism of action underlying the hemostatic effect of zeolite and its interaction with blood are not clear. Therefore, the progress of structure modification has been limited. 
Zeolite is thought to rapidly absorb water in a non-chemical reaction at the site of bleeding, which is thought to effectively concentrate platelets and clotting factors, promoting coagulation $^{[4,5]}$. However, experimental evidence of this nonchemical reaction is lacking. Ostomel et al demonstrated that an Ag-exchanged zeolite hemostat released less heat upon hydration than the parent material, but the hemostatic efficacy of the modified material was reduced. The authors suggested that the accelerated coagulation response was due to multiple factors, including plasma metabolite concentration, contact activation of the blood-clotting cascade, and the thermal warming of the injured tissue ${ }^{[8]}$, but further research is required to verify these hypotheses.

Few research has been conducted on the release of ingredients from this hemostatic agent into the blood and the effects of these materials on the hemostatic process. Our study identified zeolite-induced changes in blood electrolytes and blood coagulation in vitro.

\section{Materials and methods}

Detection of electrolytes in human blood treated with QuikClot

Fresh blood $(8 \mathrm{~mL})$ was extracted from the ulnar vein of healthy adult volunteers in a fasting state (males aged 18-20 years, $n=8$ ) in the morning. Two milliliters of each blood specimen was immediately infused into three test tubes. The tubes were mixed with $0 \mathrm{mg}$ (control group), $50 \mathrm{mg}$ or $100 \mathrm{mg}$ of QC (QuikClot, Z-Medica, Newington, CT, USA) and gently shaken for $1 \mathrm{~min}$. Each tube was maintained in a stationary position until the serum had separated out, and the serum was then collected for measuring. Electrolyte levels in the serum, such as those of $\mathrm{Na}^{+}, \mathrm{K}^{+}, \mathrm{Ca}^{2+}$, and $\mathrm{Cl}^{-}$, were measured using a blood electrolyte analyzer (BEA) (XD685, Xun-da Research Equipment Corporation, Shanghai, China).

\section{Detection of electrolytes in a saline solution treated with Quik- Clot}

The same experiments were performed in $2 \mathrm{~mL}$ of a $0.9 \% \mathrm{NaCl}$ solution (preheated to $37^{\circ} \mathrm{C}$ ). Electrolyte concentrations were measured using a BEA.

\section{ICP-AES detection of the components of a saline solution mixed} with QuikClot

QC (2 g) was added to $8 \mathrm{~mL}$ of a $0.9 \% \mathrm{NaCl}$ solution (preheated to $37^{\circ} \mathrm{C}$ ), and the mixture was immediately vortexed for $1 \mathrm{~min}$. The tube remained stationary for $10 \mathrm{~min}$, and the supernatant was collected for sampling (zeolite saline solution, ZSS). QC (2 g) was added to $8 \mathrm{~mL}$ of deionized water in accordance with the above procedures, and the supernatant was collected for use as a control (zeolite deionized water solution, ZDWS). The contents of the saline solution (SS), ZSS, deionized water solution (DWS) and ZDWS were detected using inductively coupled plasma atomic emission spectroscopy (ICP-AES) (Optima 5300DV type, Perkin-Elmer Corporation, MA, USA).

\section{Test tube method determination of the effect of ZSS on PT and} APTT

The aforementioned tests demonstrated that zeolite altered the electrolyte concentrations in both the blood and a saline solution. In the experiment outlined below, ZSS was prepared as a test sample to simulate zeolite-induced electrolyte changes in the blood serum and investigate the effects of zeolite on blood coagulation.

Three ZSS samples were prepared: in the first sample, ZSS1 group, $2 \mathrm{~g}$ of QC was immersed in $4 \mathrm{~mL}$ of a saline solution; in the second sample, ZSS2 group, $2 \mathrm{~g}$ of QC was immersed in 8 $\mathrm{mL}$ of a saline solution; and in the third sample, ZSS3 group, 2 $\mathrm{g}$ of QC was immersed in $16 \mathrm{~mL}$ of a saline solution. The $0.9 \%$ saline solution was preheated to $37^{\circ} \mathrm{C}$ in a test tube. The tube was vortexed for $1 \mathrm{~min}$ after the addition of QC to fully mix the solution. The tube remained stationary for $10 \mathrm{~min}$, after which time the supernatant was collected for sampling.

\section{Preparation of blood samples}

Eight healthy adult sheep were provided by the Experimental Animal Center of the Fourth Military Medical University (qualified permit number: 07-009) and fed a standard diet. All sheep were observed for at least 1 week to ensure that the animals were free of any drugs or chemicals that might affect coagulation activity. Fresh blood $(10 \mathrm{~mL})$ was extracted from the external jugular veins of the animals, and the samples were immediately mixed with $3.8 \%$ sodium citrate (anticoagulant) with a volume ratio of 9:1. The blood was centrifuged at 3000 rounds per minute for $10 \mathrm{~min}$ to obtain approximately $5 \mathrm{~mL}$ of platelet-poor plasma (PPP) for use as a blood specimen. Eight blood specimens were prepared, and all specimens were tested within $1 \mathrm{~h}$ of preparation. The Laboratory Animal Care and Use Committee at the Fourth Military Medical University (Xi-an, China) approved this study.

\section{Prothrombin time (PT) and activated partial thromboplastin time (APTT) detection}

The Zhongqin Shidi Scientific Instruments Corporation (Beijing) provided all reagents. All reagents, aqueous $\mathrm{CaCl}_{2}(25$ $\mathrm{mmol} / \mathrm{L})$, saline solution and ZSS were preheated to $37^{\circ} \mathrm{C}$. Ten test tubes were prepared for the testing of each blood specimen. First, $100 \mu \mathrm{L}$ of PPP was added to each tube. The PT or APTT reagents $(100 \mu \mathrm{L})$ were added and mixed with the PPP by gentle shaking of the tube. The tubes were warmed to $37^{\circ} \mathrm{C}$ in a water bath for $3 \mathrm{~min}$ and randomly assigned to one of five experimental groups (ZSS1, ZSS2, ZSS3, saline and control group; 2 tubes/group). ZSS1, ZSS2, ZSS3 and saline (20 $\mu \mathrm{L}$ of each) were then added to the test tubes, which remained stationary for $20 \mathrm{~s}$. No solutions were added to the test tube in the control group. Aqueous $\mathrm{CaCl}_{2}(100 \mu \mathrm{L})$ was added to every test tube, and the technician quantified the thrombus formation time immediately. Two samples were measured successively in each test, and the average was recorded as PT or APTT. A professional technician performed all procedures in accordance with standard protocols. The technician who 
conducted the trials was blinded to the samples until the study was complete.

\section{Effect of ZSS on blood coagulation function}

A small amount of the ZSS/SS solution was added to fresh blood to examine the effect of the sample solution on blood coagulation. The ACT and CR were recorded using a Sonoclot Coagulation and Platelet Function Analyzer (Sonoclot Analyzer, DP-2951, Sienco, CO, USA), according to standard protocols.

ZSS was prepared by the addition of $2 \mathrm{~g}$ of QC to $8 \mathrm{~mL}$ of a saline solution, according to the previously described procedure. A $0.9 \% \mathrm{NaCl}$ solution was prepared as outlined above (ie, SS).

\section{Blood collection and treatment}

Eight healthy adult volunteers (males aged 18-19 years old) were involved in this experiment. The cubital vein was punctured in the morning during a fasting state, and a catheter was implanted, using heparin as an anticoagulant. The heparin tube was closed prior to each blood sample extraction, and 5 $\mathrm{mL}$ of blood was extracted and discarded. A new syringe was used to extract a $1.5 \mathrm{~mL}$ blood specimen. Three blood specimens were extracted from each volunteer, and the samples were randomly assigned to the ZSS group, the SS group or the control group. The interval between two samplings (ie, the time for completion of one testing) was approximately $5 \mathrm{~min}$, and all of the procedures in each volunteer were completed in less than $30 \mathrm{~min}$. All 8 specimens were included in each group.

\section{Sonoclot detection}

A sample cuvette and the Sonoclot analyzer were preheated to $37^{\circ} \mathrm{C}$. Either ZSS or SS $(20 \mu \mathrm{L})$ was added to the cuvette (gbACT+TM Kit, Sienco, USA), along with $340 \mu \mathrm{L}$ of a blood specimen. For the control group, $360 \mu \mathrm{L}$ of a blood specimen was added directly to the cuvette. The instrument automatically mixed the blood solutions, and the ACT and CR were recorded.

Effect of ZSS and a $\mathrm{CaCl}_{2}$ solution on blood coagulation function The concentration of $\mathrm{Ca}^{2+}$ in ZSS (which was prepared as described in the previous experiment) was $1.0610 \mathrm{~g} / \mathrm{L}(26.5$ $\mathrm{mmol} / \mathrm{L})$, as measured using ICP. An aqueous solution of $0.29 \% \mathrm{CaCl}_{2}$, with a $\mathrm{Ca}^{2+}$ concentration that was identical to that of ZSS, was prepared.

Either ZSS or $\mathrm{CaCl}_{2}(20 \mu \mathrm{L})$ was added to the cuvette (gbACT+TM Kit, Sienco, CO, USA), and $340 \mu \mathrm{L}$ of the blood specimen was added. A blood specimen $(360 \mu \mathrm{L})$ was added directly to the cuvette in the control group. The instrument automatically mixed the blood solutions, and the ACT and CR were recorded.

\section{Statistical analysis}

All data are presented as mean \pm SEM. The SPSS 11.5 statistical software program (SPSS/Windows, SPSS Inc, Chicago,
IL, USA) was used for inter-group comparisons. Analysis of variance was used to examine differences between the groups. The LSD $t$-test was used to make multiple comparisons between groups. Significance was defined as $P<0.05$.

\section{Results}

Electrolytes were altered in human blood after the addition of QC The $\mathrm{Ca}^{2+}$ concentration increased in the blood after the addition of QC, but the $\mathrm{Na}^{+}$and $\mathrm{K}^{+}$concentrations decreased. The $\mathrm{Ca}^{2+}$ concentrations were $3.49 \pm 0.25 \mathrm{mmol} / \mathrm{L}(50 \mathrm{mg} \mathrm{QC}$ group) and $3.94 \pm 0.49 \mathrm{mmol} / \mathrm{L}(100 \mathrm{mg}$ QC group), which were much higher than the $\mathrm{Ca}^{2+}$ concentrations in the control group $(1.19 \pm 0.03 \mathrm{mmol} / \mathrm{L})(P<0.05)$. However, the $\mathrm{Na}^{+}$and $\mathrm{K}^{+}$ concentrations were significantly lower $(P<0.05)$ in the $100 \mathrm{mg}$ and $50 \mathrm{mg}$ QC groups than that in the control group. These alterations were dose-dependent. The $\mathrm{Ca}^{2+}$ concentration was higher $(P=0.016)$ in the $100 \mathrm{mg}$ QC group than that in the 50 mg QC group, but the $\mathrm{Na}^{+}$concentration was lower $(P=0.037)$ in the $100 \mathrm{mg}$ QC group than that in the $50 \mathrm{mg}$ QC group. No differences in $\mathrm{pH}$ or $\mathrm{Cl}^{-}$concentration were observed between the three groups (Table 1).

Table 1. Changes in electrolytes in blood immersed with QC.

\begin{tabular}{lccr}
\hline & & Experimental groups \\
& $50 \mathrm{mg} \mathrm{QC}$ & $100 \mathrm{mg} \mathrm{QC}$ & Control group \\
\hline $\mathrm{pH}$ & $7.44 \pm 0.03$ & $7.43 \pm 0.05$ & $7.41 \pm 0.03$ \\
$\mathrm{Ca}^{2+}(\mathrm{mmol} / \mathrm{L})$ & $3.49 \pm 0.25^{\mathrm{b}}$ & $3.94 \pm 0.49^{\mathrm{be}}$ & $1.19 \pm 0.03$ \\
$\mathrm{Na}^{+}(\mathrm{mmol} / \mathrm{L})$ & $140.71 \pm 1.94^{\mathrm{b}}$ & $138.96 \pm 1.95^{\mathrm{be}}$ & $146.08 \pm 1.34$ \\
$\mathrm{~K}^{+}(\mathrm{mmol} / \mathrm{L})$ & $3.55 \pm 0.40^{\mathrm{b}}$ & $3.49 \pm 0.35^{\mathrm{b}}$ & $3.70 \pm 0.43$ \\
$\mathrm{Cl}^{-}(\mathrm{mmol} / \mathrm{L})$ & $104.51 \pm 0.53$ & $104.40 \pm 0.85$ & $103.85 \pm 1.17$ \\
\hline
\end{tabular}

Data are presented as mean \pm SEM. ${ }^{\mathrm{b}} \mathrm{P}<0.05$ compared to the control group. ${ }^{\mathrm{e}} \mathrm{P}<0.05$ compared to the $50 \mathrm{mg} \mathrm{QC}$ group. QC, QuikClot.

\section{Electrolytes were altered in a saline solution after the addition of QC}

Electrolyte concentrations were altered in the saline solution after the addition of zeolite. No $\mathrm{Ca}^{2+}$ was detected in the saline solution without $\mathrm{QC}$, but the $\mathrm{Ca}^{2+}$ concentrations in the $50 \mathrm{mg}$ QC and $100 \mathrm{mg}$ QC groups were $0.80 \pm 0.02 \mathrm{mmol} / \mathrm{L}$ and $2.07 \pm 0.33 \mathrm{mmol} / \mathrm{L}$, respectively. The $\mathrm{Na}^{+}$concentrations in the $50 \mathrm{mg}$ QC $(147.48 \pm 0.21 \mathrm{mmol} / \mathrm{L})$ and $100 \mathrm{mg}$ QC groups $(145.15 \pm 0.56 \mathrm{mmol} / \mathrm{L})$ were significantly lower $(P<0.05)$ than the $\mathrm{Na}^{+}$concentrations in the control group $(149.10 \pm 0.06$ mmol/L). Significant differences in the $\mathrm{Ca}^{2+}$ and $\mathrm{Na}^{+}$concentrations were observed between the $50 \mathrm{mg}$ QC and $100 \mathrm{mg}$ QC groups $(P<0.05)$. No differences in the $\mathrm{pH}$ and $\mathrm{Cl}^{-}$concentrations were observed between the three groups (Table 2).

\section{Components of the saline solution mixed with QC}

None of the studied components was detected in DWS. Minute amounts of $\mathrm{Si}^{4+}(0.1389 \mathrm{~g} / \mathrm{L}), \mathrm{Al}^{3+}(0.1318 \mathrm{~g} / \mathrm{L}), \mathrm{Na}^{+}(0.0764$ 
Table 2. Changes in electrolytes in a $0.9 \% \mathrm{NaCl}$ solution immersed with QC.

\begin{tabular}{lccc}
\hline & \multicolumn{3}{c}{$\begin{array}{c}\text { Experimental groups } \\
100 \mathrm{mg} \mathrm{QC}\end{array}$} \\
& $50 \mathrm{mg} \mathrm{QC}$ & Control group \\
\hline $\mathrm{pH}$ & $7.45 \pm 0.00$ & $7.44 \pm 0.01$ & $7.45 \pm 0.01$ \\
$\mathrm{Ca}^{2+}(\mathrm{mmol} / \mathrm{L})$ & $0.80 \pm 0.02^{\mathrm{b}}$ & $2.07 \pm 0.33^{\text {be }}$ & 0 \\
$\mathrm{Na}^{+}(\mathrm{mmol} / \mathrm{L})$ & $147.48 \pm 0.21^{\mathrm{b}}$ & $145.15 \pm 0.56^{\text {be }}$ & $149.10 \pm 0.06$ \\
$\mathrm{Cl}^{-}(\mathrm{mmol} / \mathrm{L})$ & $143.35 \pm 0.15$ & $143.19 \pm 0.18$ & $143.52 \pm 0.24$ \\
\hline
\end{tabular}

Data are presented as mean \pm SEM. ${ }^{\mathrm{b}} P<0.05$ compared to the control group. ${ }^{\mathrm{e}} P<0.05$ compared to the $50 \mathrm{mg} \mathrm{QC}$ group. QC, QuikClot.

$\mathrm{g} / \mathrm{L})$ and $\mathrm{Ca}^{2+}(0.0665 \mathrm{~g} / \mathrm{L})$ were detected in ZDWS. No elements, other than $\mathrm{Na}^{+}$and $\mathrm{Cl}^{-}$, were detected in SS. $\mathrm{Na}^{+}$ $(2.6870 \mathrm{~g} / \mathrm{L}), \mathrm{Ca}^{2+}(1.0610 \mathrm{~g} / \mathrm{L}), \mathrm{Si}^{4+}(0.2434 \mathrm{~g} / \mathrm{L})$ and $\mathrm{Al}^{3+}$ $(0.2575 \mathrm{~g} / \mathrm{L})$ were detected in ZSS. The ratio of $\mathrm{Si}^{4+}$ to $\mathrm{Al}^{3+}$ in ZSS and ZDWS was approximately equal to 1 . The $\mathrm{Si}^{4+}$ and $\mathrm{Al}^{3+}$ concentrations in ZSS were not more than twice the corresponding concentrations in ZDWS. However, the $\mathrm{Ca}^{2+}$ concentration in ZSS was more than 15 times the $\mathrm{Ca}^{2+}$ concentration in ZDWS (Table 3).

Table 3. Components of the $0.9 \% \mathrm{NaCl}$ solution mixed with $\mathrm{QC}(\mathrm{g} / \mathrm{L})$.

\begin{tabular}{lllll}
\hline & SS & ZSS & DWS & ZDWS \\
\hline $\mathrm{Al}^{3+}$ & 0 & 0.2575 & 0 & 0.1318 \\
$\mathrm{Si}^{4+}$ & 0 & 0.2434 & 0 & 0.1389 \\
$\mathrm{Ca}^{2+}$ & 0 & 1.0610 & 0 & 0.0665 \\
$\mathrm{Na}^{+}$ & 3.5380 & 2.6870 & 0 & 0.0764 \\
\hline
\end{tabular}

QC, QuikClot; SS, 0.9\% NaCl solution; ZSS, zeolite saline solution; DWS, deionized water solution; ZDWS, zeolite deionized water solution. $\mathrm{Cl}$ is not listed in the table because it could not be properly detected using ICP due to methodological reasons.

\section{Effects of ZSS on PT and APTT}

APTT is commonly used for the evaluation of the intrinsic pathway of blood coagulation in the clinic. Our results demonstrated that the APTTs were $25.16 \pm 4.03 \mathrm{~s}$ (ZSS1 group), $28.51 \pm 2.47 \mathrm{~s}$ (ZSS2 group) and $32.65 \pm 2.12 \mathrm{~s}$ (ZSS3 group). The APTTs in the ZSS1 and ZSS2 groups were shorter $(P<0.05)$ than those in the ZSS3 group. However, all APTTs were significantly shorter $(P<0.05)$ than those in the SS $(41.53 \pm 3.37 \mathrm{~s})$ and control groups $(40.94 \pm 3.09 \mathrm{~s})$. The APTT for the SS group was not significantly different from that of the control group. No difference in PT was observed between the groups (Table 4).

\section{Effect of ZSS on blood coagulation function}

The average ACT for the ZSS group (106.38 $\pm 18.10 \mathrm{~s})$ was significantly shorter $(P<0.05)$ than that of the control group $(178.88 \pm 22.39 \mathrm{~s})$. The ACT of the SS group was not significantly different from that of the control group. No differences in the $\mathrm{CR}$ were observed between the three groups (Table 5).

Table 5. Effect of ZSS and SS on blood coagulation function.

\begin{tabular}{|c|c|c|c|}
\hline & \multicolumn{3}{|c|}{ Experimental groups } \\
\hline & ZSS & SS & Control group \\
\hline ACT (s) & $106.38 \pm 18.10^{\text {be }}$ & $173.50 \pm 25.46$ & $178.88 \pm 22.39$ \\
\hline CR & $16.70 \pm 2.46$ & $15.63 \pm 3.82$ & $15.99 \pm 2.33$ \\
\hline
\end{tabular}

Data are presented as mean \pm SEM. ${ }^{\mathrm{b}} P<0.05$ compared to the control group. ${ }^{\mathrm{e}} \mathrm{P}<0.05$ compared to the SS group. ZSS, zeolite saline solution; $\mathrm{SS}, 0.9 \% \mathrm{NaCl}$ solution; Control group, no solution; $\mathrm{ACT}$, activated clotting time; $\mathrm{CR}$, clotting rate.

Effect of ZSS and a $\mathrm{CaCl}_{2}$ solution on blood coagulation function The average ACTs for the ZSS and $\mathrm{CaCl}_{2}$ groups were $103.14 \pm 19.61 \mathrm{~s}$ and $112.13 \pm 20.40 \mathrm{~s}$, respectively. These ACTs were all significantly shorter $(P<0.05)$ than the ACTs in the control group (163.47 $\pm 17.42 \mathrm{~s})$. The ACT for the ZSS group was not significantly different $(P=0.47)$ from that of the $\mathrm{CaCl}_{2}$ group. No differences in the $\mathrm{CR}$ were observed between the three groups (Table 6).

\section{Discussion}

The active component of $\mathrm{QC}$ is zeolite linde type $5 \mathrm{~A}^{[8]}$. Zeolite $5 \mathrm{~A}$ has an empirical formula of $\mathrm{Na}_{0.4} \mathrm{Ca}_{5.8}\left(\mathrm{SiO}_{2}\right)_{12}\left(\mathrm{AlO}_{2}\right)_{12} \cdot 27$ $\mathrm{H}_{2} \mathrm{O}$ when fully hydrated, and the ratio of $\mathrm{Si}: \mathrm{Al}$ is equal to 1 . Low concentrations of $\mathrm{Si}^{4+}, \mathrm{Al}^{3+}, \mathrm{Na}^{+}$, and $\mathrm{Ca}^{2+}$ were detected in ZDWS by using ICP-AES. These elements were derived from zeolite because ZDWS is composed only of deionized

Table 4. Effect of ZSS on PT and APTT in sheep blood.

\begin{tabular}{|c|c|c|c|c|c|}
\hline & \multicolumn{5}{|c|}{ Experimental groups } \\
\hline & ZSS1 & ZSS2 & ZSS3 & SS & Control group \\
\hline PT (s) & $13.34 \pm 2.62$ & $13.15 \pm 1.70$ & $13.75 \pm 1.63$ & $14.38 \pm 2.05$ & $14.46 \pm 1.52$ \\
\hline APTT (s) & $25.16 \pm 4.03^{\text {be }}$ & $28.51 \pm 2.47^{\text {be }}$ & $32.65 \pm 2.12^{b}$ & $41.53 \pm 3.37$ & $40.94 \pm 3.09$ \\
\hline
\end{tabular}

Data are presented as mean \pm SEM. ${ }^{\mathrm{b}} \mathrm{P}<0.05$ compared to the control group. ${ }^{\mathrm{e}} \mathrm{P}<0.05$ compared to the ZSS3 group. ZSS1, 2 g of QC was immersed in $4 \mathrm{~mL}$ of SS. ZSS2, $2 \mathrm{~g}$ of QC was immersed in $8 \mathrm{~mL}$ of SS. ZSS3, $2 \mathrm{~g}$ of QC was immersed in $16 \mathrm{~mL}$ of SS. SS, $0.9 \% \mathrm{NaCl}$ solution. Control group, no solution. PT, prothrombin time. APTT, activated partial thromboplastin time. 
Table 6. Effect of ZSS and $\mathrm{CaCl}_{2}$ solution on blood coagulation function.

\begin{tabular}{lccc}
\hline & & Experimental groups \\
& ZSS & $\mathrm{CaCl}_{2}$ & Control group \\
\hline $\mathrm{ACT}(\mathrm{s})$ & $103.14 \pm 19.61^{\mathrm{b}}$ & $112.13 \pm 20.40^{\mathrm{b}}$ & $163.47 \pm 17.42$ \\
$\mathrm{CR}$ & $16.01 \pm 3.35$ & $14.56 \pm 2.53$ & $15.86 \pm 3.21$ \\
\hline
\end{tabular}

Data are presented as mean \pm SEM. ${ }^{b} P<0.05$ compared to the Control group. ZSS, zeolite saline solution; $\mathrm{CaCl}_{2}$, aqueous solution of the $\mathrm{CaCl}_{2}$; Control group, no solution; $\mathrm{ACT}$, activated clotting time; $\mathrm{CR}$, clotting rate.

water. Similarly, the detected $\mathrm{Ca}^{2+}$ in ZSS and the increase in the amount of $\mathrm{Ca}^{2+}$ detected in the blood were also derived from zeolite.

Generally, the constituents of a solute escape into an aqueous solution in one of two ways: physical dissolution or chemical reaction. The increase in the $\mathrm{Si}^{4+}, \mathrm{Al}^{3+}, \mathrm{Na}^{+}$, and $\mathrm{Ca}^{2+}$ concentrations in ZDWS must have, therefore, been derived from the dissolution of a small portion of zeolite because deionized water does not chemically react with zeolite. The $\mathrm{Al}^{3+}, \mathrm{Si}^{4+}$, and $\mathrm{Ca}^{2+}$ concentrations were higher in ZSS than those in ZDWS, and the $\mathrm{Na}^{+}$concentration was lower. These changes were due to a cation exchange reaction between the zeolite and the $\mathrm{NaCl}$ solution.

Cation exchange is a fundamental chemical property of zeolite. A unit cell of zeolite linde type $5 \mathrm{~A}$ is built from 12 silica and 12 alumina tetrahedral molecules that are bonded through shared oxygen atoms. The silicon in the silicon-oxygen tetrahedron was a quadrivalent cation, and the oxygen was a monovalent anion. Therefore, the tetrahedron was charge neutralized. The aluminum in the aluminum-oxygen tetrahedron was a trivalent cation. Therefore, the tetrahedron was negatively charged. Zeolite 5A usually absorbs metal ions, such as $\mathrm{Na}^{+}$, $\mathrm{Ca}^{2+}$ and $\mathrm{Mg}^{2+}$, in the open porous internal space to achieve a neutral charge. However, this combination is relatively weak, and the absorbed ions are readily exchanged with metal ions in solution. The cation exchange reaction is affected by several conditions, such as the metal ion concentration in the solution and the reaction temperature.

The addition of QC to either the blood or a $0.9 \% \mathrm{NaCl}$ solution causes the release of the $\mathrm{Ca}^{2+}$ that is contained in zeolite into the blood or the solution and its replacement with $\mathrm{Na}^{+}$ and $\mathrm{K}^{+}$. This exchange may explain the increase in $\mathrm{Ca}^{2+}$ concentration and the decrease in $\mathrm{Na}^{+}$and $\mathrm{K}^{+}$concentrations in the blood and the $\mathrm{NaCl}$ solution following the addition of QC. This mechanism may also explain the absence of significant changes in $\mathrm{Cl}^{-}$concentration and $\mathrm{pH}$. The $\mathrm{Si}^{4+}$ and $\mathrm{Al}^{3+}$ concentrations in ZSS were approximately two times higher than the concentrations in ZDWS. However, the $\mathrm{Ca}^{2+}$ concentration in ZSS was approximately sixteen times the concentration in ZDWS, and the $\mathrm{Na}^{+}$concentration was significantly decreased. We inferred that $\mathrm{Si}^{4+}$ and $\mathrm{Al}^{3+}$ were released through the physical dissolution of a small amount of zeolite in ZSS, which was similar to the mechanism that occurred in ZDWS, but that $\mathrm{Ca}^{2+}$ was primarily released through a cation exchange reaction.
Our results demonstrated for the first time that the $\mathrm{Ca}^{2+}$ in zeolite is released into the blood and into a $\mathrm{NaCl}$ solution upon contact, as a result of a cation exchange reaction. This result provided the basis for the use of ZSS in further examinations of the impact of electrolyte changes on blood coagulation.

Blood clotting after vascular injury is a complex process that involves blood vessels, platelets, coagulation factors and the interaction of these factors. PT and APTT are the most commonly used indicators for the clinical evaluation of the extrinsic and intrinsic pathways of blood coagulation, respectively, according to the classical coagulation cascade model ${ }^{[10]}$.

We demonstrated that the APTT was shortened in all three of the ZSS groups using the test tube method, which suggested that ZSS accelerated the intrinsic pathway of blood coagulation. These results may be due to increased $\mathrm{Ca}^{2+}$ concentrations in ZSS. We assumed that the increase in $\mathrm{Ca}^{2+}$ concentration in ZSS would speed up the intrinsic pathway of blood coagulation by promoting the interaction of coagulating proteins. However, this hypothesis requires further investigation.

The Sonoclot analyzer is the most advanced instrument for the in vitro measurement of coagulation and platelet function in whole blood. This method provides accurate data on the entire hemostasis process, including coagulation, fibrin gel formation, clot retraction, and fibrinolysis. Therefore, this technique is used in a wide range of clinical and research applications, including cardiovascular surgery, liver transplant surgery, obstetrics, coagulation labs, hypercoagulable screening, and trauma applications.

Each Sonoclot analysis generates a qualitative graph, known as the Sonoclot Signature, as well as quantitative results on clot formation time (activated clotting time - onset, ACT) and the rate of fibrin polymerization (clot rate, CR). The ACT represents the time that the test sample remains a liquid. Fibrinogen is converted to fibrin monomers once thrombin forms in the test sample, and these monomers spontaneously polymerize to form a fibrin gel. The clot rate $(\mathrm{CR})$ represents the rate of fibrin polymerization.

The ACT was significantly shorter in the ZSS group than that in the control group, but the CR was unchanged. These results suggested that ZSS accelerates the coagulation cascade mainly by increasing the rate of initial fibrin formation. However, fibrin polymerization was not affected. The previous experiment demonstrated that ZSS shortened the APTT. The mechanism underlying the shortened ACT may be attributed to the accelerating effect of ZSS on the intrinsic coagulation pathway.

We compared the effects of ZSS and an aqueous $\mathrm{CaCl}_{2}$ solution containing the same concentration of $\mathrm{Ca}^{2+}$ as the ZSS on the ACT and CR, to further examine whether the above effects of ZSS were related to decreases in $\mathrm{Na}^{+}, \mathrm{K}^{+}$, or other components, such as $\mathrm{Si}^{4+}$ and $\mathrm{Al}^{3+}$. The results demonstrated that there were no differences in the ACT and CR between the two groups. Therefore, the increase in $\mathrm{Ca}^{2+}$ may be the key factor for the procoagulant effects of ZSS. 
Our study is the first to report the use of the Sonoclot analyzer for the evaluation of ZSS-induced blood clot formation. Our method exhibits some advantages. First, the use of fresh whole blood as a specimen precluded interference from the addition of anticoagulants or from blood separation. Therefore, the use of fresh whole blood more objectively revealed QC's blood coagulation function. Second, the clotting parameters ACT and CR exhibited dynamic changes in the blood coagulation process, which contributed to the analysis of the primary hemostatic effects of zeolite. Third, this method was rapid and simple to use, and the results were quantitative and reliable. The Sonoclot analyzer may be a reliable ancillary means for the investigation of the mechanisms of hemostatic agents and the analysis of hemostatic efficacy in vitro.

Therefore, these results suggest that not only the physical properties, such as the absorption of water and the concentration of coagulating factors, but also the chemical composition, especially the $\mathrm{Ca}^{2+}$ concentration, play important roles in the procoagulant actions of zeolites. These mechanisms may partially explain the results of Ostomel et al's study, in which the exchange of $\mathrm{Ca}^{2+}$ with $\mathrm{Ag}^{+}$in a zeolite hemostatic agent reduced the heat of hydration, but impaired hemostatic efficacy $^{[8]}$. This feature may be especially valuable for cases that are complicated by a $\mathrm{Ca}^{2+}$ deficiency-induced coagulopathy, such as patients who endure excessive bleeding. Our results also provide a basis for the further improvement of zeolite agents via alterations in chemical composition.

The limitations of this study include the limited group sizes that were used to explore zeolite-induced electrolyte changes in the blood and the effect of zeolite on clot formation. The relationship between zeolite dose and blood coagulation is not clear, and the impact of $\mathrm{Ca}^{2+}$ dose on zeolite-induced hemostasis requires further study.

In summary, zeolite released $\mathrm{Ca}^{2+}$ and absorbed $\mathrm{Na}^{+}$and $\mathrm{K}^{+}$ upon contact with the blood via a cation exchange reaction. The increase in $\mathrm{Ca}^{2+}$ shortened both the APTT and clot formation time in vitro. Cation exchange is an important mechanism of action underlying the hemostatic effect of zeolite.

\section{Acknowledgements}

We would like to acknowledge the invaluable guidance and support provided by Qi-bing MEI, PhD (Department of Pharmacology, Fourth Military Medical University) and Dr Shujun HAN, MD (Department of Anesthesiology, General Hospi- tal of Armed Police Forces). We also gratefully acknowledge the superb technical assistance provided by Ping HUANG (Department of Laboratory Medicine, School of Stomatology, Fourth Military Medical University).

\section{Author contribution}

Shao-zong CHEN and Xue-yong LI designed the research; Jing LI performed the research and wrote the manuscript; Wei CAO participated in the experiments; Xiao-xing LV analyzed the data; Li JIANG contributed new analytical tools and reagents; Yue-jun LI supervised the experiments; and Wangzhou LI was responsible for revising the manuscript.

\section{References}

1 Alam HB, Chen Z, Jaskille A, Querol RI, Koustova E, Inocencio R, et al. Application of a zeolite hemostatic agent achieves $100 \%$ survival in a lethal model of complex groin injury in swine. J Trauma 2004; 56: 974-83.

2 Pusateri AE, Delgado AV, Dick EJ Jr, Martinez RS, Holcomb JB, Ryan KL. Application of a granular mineral-based hemostatic agent (QuikClot) to reduce blood loss after grade $\mathrm{V}$ liver injury in swine. J Trauma 2004; 57: 555-62.

3 Inaba K, Rhee P, Teixeira PG, Barmparas G, Putty B, Branco BC, et al. Intracorporeal use of advanced local hemostatics in a damage control swine model of grade iv liver injury. J Trauma 2011; 71: 1312-8.

4 Rhee P, Brown C, Martin M, Salim A, Plurad D, Green D, et al. QuikClot use in trauma for hemorrhage control: case series of 103 documented uses. J Trauma 2008; 64: 1093-9.

5 Alam HB, Burris D, DaCorta JA, Rhee P. Hemorrhage control in the battlefield: role of new hemostatic agents. Mil Med 2005; 170: 63-9.

6 Wright JK, Kalns J, Wolf EA, Traweek F, Schwarz S, Loeffler CK, et al. Thermal injury resulting from application of a granular mineral hemostatic agent. J Trauma 2004; 57: 224-30.

7 Wright FL, Hua HT, Velmahos G, Thoman D. Intracopreal use of the hemostatic agent QuickClot in a coagulopathic patient with combined thoracoabdominal penetrating trauma. J Trauma 2004; 56: 205-8.

8 Ostomel TA, Stoimenov PK, Holden PA, Alam HB, Stucky GD. Hostguest composites for induced hemostasis and therapeutic healing in traumatic injuries. J Thromb Thrombolysis 2006; 22: 55-67.

9 Mortazavi SM, Atefi A, Roshan-Shomal P, Raadpey N, Mortazavi G. Development of a novel mineral based haemostatic agent consisting of a combination of bentonite and zeolite minerals. J Ayub Med Coll Abbottabad 2009; 21: 3-7.

10 Hoffman R, Benz EJ jr, Shattil SJ. Hematology: Basic principles and practice, 4th ed. Philadelphia, PA: Elsevier, Churchill Livingstone; 2005. 